ISSN: 2224-0616

Int. J. Agril. Res. Innov. \& Tech. 1(1\&2): 1-8, December, 2011 Available online at http:// www.ijarit.webs.com

\title{
SUSTAINABLE AGRICULTURE: A CHALLENGE IN BANGLADESH
}

\author{
M.A.A. Faroque ${ }^{1 *}$, M.A. Kashem² and S.E. Bilkis ${ }^{3}$
}

Received 3 July 2011, Revised 10 November 2011, Accepted 25 December 2011, Published online 31 December 2011

\begin{abstract}
The sustainability of conventional agriculture in Bangladesh is under threat from the continuous degradation of land and water resources, and from declining yields due to indiscriminate use of agro-chemicals. Government is pursuing efforts to promote sustainable agriculture with emphasis on better use of on-farm resources and the reduction of external inputs. This paper presents four dimensions of agricultural sustainability as productivity, environmental stability, economical profitability, and social and economic equity. Six characters were selected to evaluate sustainability. Significant differences were found between the two systems (conventional and sustainable agriculture) in crop diversification, soil fertility management, pests and diseases management, use of agrochemicals and environmental issues. However, no significant variations were found in other indicators such as land-use pattern, crop yield and stability, risk and uncertainties, and food security. Although crop yield and financial return were found to be slightly higher in the conventional system, the economic return and value addition per unit of land did not show any difference. It can be suggested that sustainable agriculture has a tendency towards becoming environmental, economically and socially more sound than conventional agriculture, as it requires considerably less agro-chemicals, adds more organic matter to the soil, provides balanced food, and requires higher local inputs without markedly compromising output and financial benefits. Broad-policy measures, including the creation of mass awareness of adverse health effects of agrochemical-based products, are outlined for the promotion of sustainable agriculture.
\end{abstract}

Keywords: Sustainable Agriculture, Bangladesh

${ }^{1}$ Personal Secretary to Director, Project Implementation Unit, National Agricultural Technology Project, Bangladesh Agricultural Research Council, Farmgate, Dhaka-1215, Bangladesh; ${ }^{2}$ Principal Scientific Officer, TTMU, and Director, Project Implementation Unit, National Agricultural Technology Project, Bangladesh Agricultural Research Council, Farmgate, Dhaka-1215, Bangladesh; ${ }^{3}$ Technical Officer, Project Implementation Unit, National Agricultural Technology Project, Bangladesh

*Corresponding author's email: faroque_kbd2004@yahoo.com

Reviewed by Dr. Md. Towhidul Islam, Bangladesh Water Development Board, Mymensingh, Bangladesh

\section{Introduction}

Bangladesh agriculture has changed dramatically, especially since the end of Independent War. Crops productivity soared due to new technologies, mechanization, increased chemical use, specialization and government policies that favoured maximizing production (ASR, 2006). These changes allowed fewer farmers with reduced labour demands to produce the majority of the crops in Bangladesh.

Although these changes have many positive effects and reduced many risks in farming, there have also been significant increased costs viz. top soil depletion, ground and surface water contamination, continued neglect of the living and working conditions for farm labours, increasing costs of production, and the disintegration of economic and social conditions in rural communities (ASR, 2006) .

A growing movement has emerged during the past two decades to question the role of the agricultural establishment in promoting practices that contribute to these social problems. Now a day the movement for sustainable agriculture is gaining increasing support and acceptance within mainstream agriculture. Not only sustainable agriculture address many environmental and social concerns, but it offers innovative and economically viable opportunities for growers, laborers, consumers, policy makers and many others in the entire food system with concerning congenial environment. 
Necessity of Sustainable agriculture for present contest include i) providing a more profitable farm income; ii) promoting environmental stewardship (protecting and improving soil quality, reducing dependence on non-renewable resources, such as fuel and synthetic fertilizers and pesticide and minimizing adverse impacts on safety, wildlife, water quality an other environmental resource iii) reducing loss of biodiversity and agricultural genetic diversity. The progress of sustainable agriculture is not mentionable. Sustainable agriculture appears in NGO levels as its ecological farming system. The government initiated some programs with support from different aid agencies from very recent. Research on sustainable agriculture was done very few in NGO level.

This paper is an effort to present the ideas, practices and policies that constitute our concept of sustainable agriculture to clarify the research agenda and suggest the practical steps that may be appropriate for moving toward sustainable agriculture.

\section{Historical development of agriculture in Bangladesh}

Bangladesh agriculture has achieved significant structural changes over the past three and half decades. Despite many problems and constraints a quiet agricultural revolution has taken place which is still evolving in response to natural calamities, sociopolitical changes, population growth, urbanization, new technology in agriculture and new opportunities in rural nonagriculture sector, commercialization and changes in macro policy and sector policy reforms including market and trade liberalization and substantial reduction in public sector intervention in agriculture (ASR, 2006). From largely a peasant based subsistence activity, agriculture today is more of a commercial entrepreneurial activity than ever before. Cereal grain production increased three folds. Growth of non-cereals, mostly horticultural products accelerated. The great observation of the increasing phenomenon of diversification and intensification of Bangladesh agriculture.

Technological change coupled with market forces greatly influenced Bangladesh agriculture in midsixties and seventies. From a relatively stagnant sector in the pre-green revolution period, Bangladesh agriculture emerged as a dynamic sector in the green revolution period. There was a significant growth in agriculture infrastructure as well as a shift towards liberalization from government control. Total rice production in 1971 was 10 million tons; in 2008-2009 it was 31.50 million tons (BER, 2009). The net result is that the country has gone from a situation of chronic deficit to near self-sufficiency. Cropping intensity increased from $181 \%$ in 2008-2009 (BBS, 2008). Long-term trend of rice production shows that the dominant factor in grouth is rice yield, stimulated by high yielding varieties (HYV), fertilizer, and irrigation technology. Investment in research was small, yet there was technological progress, as evidenced by release of 58 HYV rice varieties by BRRI/BINA/Universities and 473 high yielding varieties of various crops by different research institutes. Extension too played a role although the much discussed, the lesson being that market should spread new technology, farmers should seek out extension with queries and problems and agents should be there to assist. Chemical fertilizer and pesticide use became popular across all groups of farmers form 1971. Integration of variety-fertilizer-irrigation development was a major factor behind spread of HYV and consequent yield increase. Other concurrent developments include increasing mechanization of agricultural operations, including power tillers for cultivation, pumps for irrigation and threshers and rice mills for converting paddy into rice. These technologies are now concern to use them an integrated manner get sustainability in agriculture.

"Sustainable agriculture means an integrated system of plant and animal production practices having a site-specific application that over the long term will: Satisfy human food and fiber need, enhance environmental quality and the natural resource base upon which the agricultural economy depends, make the most efficient use of non renewable resources and onfarm resources and integrate, where appropriate, natural biology cycles and controls, sustain the economic viability of farm operations, enhance the quality of life for farmers and society as a whole" (USDA Farm Bill, 1990).

"Sustainable agriculture is one that produces abundant food with depleting the earth's resources or polluting its environment. It is agriculture that follows the principles of nature to form systems for raining crops and livestock that are, like nature, self-sustaining. Sustainable agriculture is also the agriculture of social values, one whose success is indistinguishable from vibrant rural communities, rich lives for families on the farm, and wholesome a food for everyone." (ATTRA-National Sustainable Agriculture Information Service).

\section{Characteristics of sustainable agriculture}

Sustainable agriculture is a way of raising food production that is healthy for men and animals, does not harm the environment, is humanitarian for workers, respects animals, and provides a fair wage to the farmer (www.sustainabletable.org). 
1. Conservation and preservation: Out put of the environment is put back in, so land and resources such as water, soil and air can be replenished and are available to future generations. The waste from sustainable farming stays within the farm's ecosystem and cannot cause buildup or pollution. So, judicial use of fertilizer, water, minimum emission of GHGs is needed. In addition, sustainable agriculture seeks to minimize transportation costs and fossil fuel use, and is as locally-based as possible. Technical intervention with minimum hazard.

2. Biodiversity: Farms raise different types of plants and animals, which are rotated around the fields to enrich the soil and help prevent disease and pest outbreaks. Chemical pesticides are used minimally and only when necessary; many sustainable farms do not use any form of chemicals.

3. Animal welfare: Animals are treated humanely and with respect, and are well cared for. They are permitted to carry out their natural behaviors, such as grazing, rooting or pecking, and are fed a natural diet appropriate for their species.

4. Economically viable: Farmers are paid a fair wage and are not dependent on subsidies from the government. Sustainable farmers help strengthen rural communities.

5. Socially just: Workers are treated fairly and paid competitive wages and benefits. They work in a safe environment and are offered proper living conditions and food.

\section{Productivity/Capacity:} productivity to feed the people with minima environmental hazards.

\section{Present status of sustainable agriculture in Bangladesh}

Before the advent of Green Revolution during 60's Bangladeshi farmers did not use any chemical fertilizers or pesticides. Since than the farmers gradually had used chemicals in their farms. As the consequences of chemical farming were emerging some organizations started their activities (PROSHIKA, CARITAS, and UBINIG etc.). The government also started integrated crop management (ICM) and integrated pest management (IPM) project to minimize the use of chemical fertilizers and pesticides.

However, the extent of sustainable agriculture is too low till today. Sustainable agriculture emerged as an issue during 1976 when PROSHIKA (a leading NGO of Bangladesh) started its ecological farming program. The government through Department of Agriculture Extension (DAE) implemented few projects with support from different aid agencies during 90's. Since climatic diseases are occurring crop loss every year and also for the change in agricultural pattern (from subsistence to heavily dependent on input oriented agriculture. There are several other NGOs and commercial organizations are dealing with farming and marketing of organic agriculture and products. CARE-Bangladesh had few projects to address sustainable agriculture issue such as GOLDA, GO-INTERFISH, and NOPEST, which contributed much in this regard. Currently they have SHABGE, LMP and Akti Bari Akti Khamar project in operation with some components of sustainable agriculture. There was a networking organization (currently inactive) called Forum of Regenerative Agricultural Movement (FoRAM) and Bangladesh Rural Reconstruction Association (BARRA) worked in this field (DFID, 2001).

\section{Goals of sustainable agriculture}

Sustainable agriculture integrates four main goals:

1. Productivity,

2. Environmental stability,

3. Economic profitability, and

4. Social and economic equity.

Many different terms have used to imply greater sustainability in agricultural systems than in prevailing systems (both pre-industrial and industrializes). Each emphasizes different values, priorities and practices (Pretty, 1995, 2002).

One most important component of agricultural sustainability is productivity. Productivity means capability of farm production. It is related to judicial use of soil, water, propagation materials, labours, fertilizers and cost.

Second, interpretation of sustainable agriculture focuses on types of technology in particular setting, especial strategies that reduce reliance on non-renewable or environmentally harmful inputs. These include eco-agriculture, permaculture, organic, ecological, low-input, biodynamic, environmentally-sensitive, community-based, farm-fresh and extensive strategies. There is intense debate, however, about whether agricultural systems using some of these terms actually qualify as "sustainable". Ecological- the core concerns are to reduce negative environmental and health externalities, to enhance and use local ecosystem resources, and preserve biodiversity. More recent concerns include broader recognition for positive environmental externalities from agriculture.

Third, Economic perspectives on agricultural sustainability seek to assign value to ecological assets, and also to include a longer time frame in economic analysis. They also highlight subsidies that promote the depletion of resources or unfair competition with other production systems. 
Forth and broader interpretation-which is used in this paper-focus more on the concept of agricultural sustainability, and social \& economical equity. Socio-economical and political-there are many concerns about the equality of technological change. At the local level, agricultural sustainability is associated with farmer participation, group action and promotion of local institutions, culture and farming communities. At the higher level, the concern is for enabling policies that target poverty reduction.

Sustainable agriculture implies the capacity to adapt and change as external and internal conditions change. The conceptual parameters have broadened from focus on environmental aspects to include first productivity and then wider social and economical dimensions. These four goals of sustainable agricultural are relative dimension depends on time, place, socioeconomical and political condition. Key features of agricultural sustainability include an acceptance of the fact that agricultural strategies should be based on more than simple productivity criteria, that externalities in assessing agricultural change (DFID, 2002).

Finally, it is important to point out that reaching toward the goal of sustainable agriculture is the responsibility of all participants in the system, including farmers, laborers, policy makers, researchers, retailers, and consumers. Each group has its own part to play, its own unique contribution to make to strengthen the sustainable agriculture community. Sustainability in agriculture need to address at farm level, national level, and regional level. The following indicative model (Fig.1) is important.

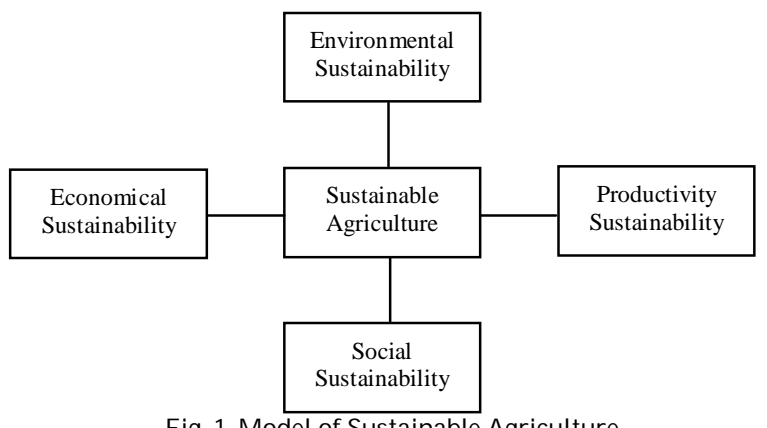

Fig. 1. Model of Sustainable Agriculture

\section{Strategies of sustainable agriculture}

The strategies are grouped according to three separate areas of concern:

I. Management of Natural Resources,

II. Production Practices (crops, livestock and fisheries), and

III. The Economic, Social and Political Context.

\section{Management of natural resources}

Agriculture is the most important user of natural resources like soil, water, air and energy, and its sustainability depends upon their availability (DFID, 2002).

Soil management: A common philosophy among sustainable agriculture practitioners is that a "healthy" soil is a key component of sustainability; that is, a healthy soil will produce healthy crop plants that have optimum vigor and are less susceptible to pests. Crop management systems that improve soil quality often result in greater inputs of water, nutrients, pesticides, and/or energy for tillage to maintain yields. In sustainable systems-

- The soil is a fragile and living medium that must be protected and nurtured to ensure its long-term productivity and stability,

- To protect and enhance the productivity of the soil include using cover crops, compost and/ or manures, reducing tillage, avoiding traffic on wet soils, and maintaining soil cover with plants and/ or mulches,

- Regular additions of organic matter or the use of cover crops can increase soil aggregate stability and diversity of soil microbial life,

Water: Water is the principal resource that has helped agriculture and society to prosper, and it has been a major limiting factor when mismanaged. There is no proper guidelines and management actions of water use in agriculture. But water supply and use is very important in sustainable agriculture in both wet and dry season. We can practice some actions in sustainable agriculture-

- improving water conservation and storage,

- providing incentives for selection of droughttolerant crop species,

- increasing water use efficiency, and

- managing crops to reduce water loss, or not planting at all.

The most important issues related to water quality involve salinization and contamination of ground and surface waters by pesticides, nitrates and heavy metal. Salinity has become a problem wherever water of even relatively low salt content is used on shallow soils where the water table is near the root zone of crops. Tile drainage can remove the water and salts, but the disposal of the salts and other contaminants may negatively affect the environment depending upon where they are deposited. Temporary solutions include-

- the use of salt-tolerant crops,

- low-volume irrigation, and

- various management techniques to minimize the effects of salts on crops. 
In the long-term, some land may need to be

- removed from production or converted to other uses,

- other uses include conversion of row crop land to production of drought-tolerant forages,

- the restoration of wildlife habitat or the use of agro-forestry to minimize the impacts of salinity and high water tables.

Energy: Modern agriculture is heavily dependent on non-renewable energy sources, especially fossil fuel. The continued use of these energy sources cannot be sustained indefinitely, yet to abruptly abandon our reliance on them would be economically catastrophic. However, a sudden cut off in energy supply would be equally disruptive. In sustainable agricultural systems, there is reduced reliance on non-renewable energy sources and a substitution of renewable sources or labour to the extent that is economically feasible.

Air: Many agricultural activities affect air quality. These include emission of GHGs and smoke from agricultural burning; dust from tillage, traffic and harvest; pesticide drift from spraying; and nitrous oxide emissions from the use of nitrogen fertilizer. Options to improve air quality include

- incorporating crop residue into the soil,

- using appropriate levels of tillage,

- planting wind breaks,

- cover crops or strips of native perennial grasses to reduce dust, and

- reducing the emission of GHGs from industries and transport and mechanical agricultural.

Efficient use of inputs: Many inputs and practices used by conventional farmers are also used in sustainable agriculture. However, maximize reliance on natural, renewable, and on-farm inputs is the prerequisite. Equally important are the environmental, social, and economic impacts of a particular strategy. Converting to sustainable practices does not mean simple input substitution. Frequently, it substitutes enhanced management and scientific knowledge for conventional inputs, especially chemical inputs that harm the environment on farms and in rural communities. The goal is to develop efficient biological systems which also maximize the efficiency of input use to maintain productivity and profitability.

\section{Production practices Crops}

Sustainable production practices involve a variety of activities/approaches such as topography, soil characteristics, climate, pests, local availability of inputs and the individual grower's goals. Despite the site-specific and individual nature of sustainable agriculture, several general principles can be applied to help growers selecting appropriate management practices:

- Selection of species and varieties that is well suited to the site and to conditions on the farm,

- Intensification and diversification of crops (including livestock and fisheries) and cultural practices to enhance the biological and economic sustainability of the farm,

- Proper agronomic management,

- Efficient use of inputs, and

- Consideration of farmers' goals and lifestyle choices.

\section{Livestock}

Bangladesh agriculture is characterized as mix farming which integrated crop, livestock and fish. This is the result of a trend toward separation and specialization of crop and animal production systems is dominating day by day. The actual management practices will, of course, be quite different. Some of the specific points that livestock producers need to address are listed below.

- Management/planning including the mobility of the stock, daily feeding, health concerns, breeding operations, seasonal feed and forage sources, and complex marketing are sources of this complexity.

- Animal enterprise must be appropriate for the farm resources. Farm capabilities and constraints such as feed and forage sources, landscape, climate and skill of the manager must be considered in selecting which animals to produce.

- There is a wide range of breeds available in each of the major ruminant species, i.e., cattle, sheep and goats.

- Use of quality germplasm to improve herd performance is another key to sustainability. In combination with good genetic stock, adapting the reproduction season to fit the climate and sources of feed and forage reduce health problems and feed costs.

- Animal nutrition feed costs are the largest single variable cost in any livestock operation.

- Animal health greatly influences reproductive success and weight gains, two key aspects of successful livestock production. A herd health program is critical to sustainable livestock production.

- Most adverse environmental impacts associated with grazing can be prevented or mitigated with proper grazing management.

\section{Fisheries}

Rice and fish have been an essential part of the life of Bangladeshi people from time immemorial. The staple foods of the people of 
Bangladesh are rice and fish. Rice is the foremost agricultural crop in Bangladesh with an annual production of over 25.0 million tons per annum (BRRI, 2010), while annual fish production is 2.70 million tons (DoF, 2010). The demand for rice and fish is constantly increasing in Bangladesh with nearly three million people being added each year to the population of the country (Chowdhury, 2009). Nevertheless, integrated crop-livestock-fish farming offers a solution to this problem by contributing to food, income and nutrition. The carrying capacities of these lands and waters are not fully utilized, but there exists tremendous scope for increasing fish production by integrating aquaculture-farming because of the availability of low-lying rice fields, warm climate and fertile soil. Sustainable fish production practices involve a variety of activities/approaches such as soil characteristics, local demand. Despite the site-specific and individual nature of sustainable fish farming system, several general principles can be applied to help growers selecting appropriate management practices:

- Selection of species that is well suited to the site and to conditions on the farm,

- Intensification and diversification of fishes (including crops),

- Proper management,

- Efficient use of inputs, and

- Consideration of farmers' goals.

\section{The economic, social \& political context}

In addition to strategies for preserving natural resources and changing production practices, sustainable agriculture requires a commitment to changing public policies, economic institutions, and social values. Strategies for change must take into account the complex, reciprocal and everchanging relationship between agricultural production and the broader society.

The "food system" extends far beyond the farm and involves the interaction of individuals and institutions with contrasting and often competing goals including farmers, researchers, input suppliers, farm workers, unions, farm advisors, processors, retailers, consumers, and policymakers. Relationships among these actors shift over time as new technologies spawn economic, social and political changes.

A wide diversity of strategies and approaches are necessary to create a more sustainable food system. These will range from specific and concentrated efforts to alter specific policies or practices, to the longer-term tasks of reforming key institutions, rethinking economic priorities, and challenging widely-held social values. Areas of concern where change is most needed.

Government policies sometimes often obstruct the goals of sustainable agriculture. New policies are needed to simultaneously promote environmental health, economic profitability, and social and economic equity. For example, commodity and price support programs could be restructured to allow farmers to realize the full benefits of the productivity gains made possible through alternative practices. Tax and credit policies could be modified to encourage a diverse and decentralized system of family farms rather than corporate concentration and absentee ownership. Government and land grant institute research policies could be modified to emphasize the development of sustainable alternatives. Marketing orders and cosmetic standards could be amended to encourage reduced pesticide use. As the agricultural is a risky business crop insurance policy may be adopted to boast up the production.

Now a day, it is very important to protected agricultural land from industrialization and urbanization. We should be used existing land through sustainable practices and a long-term perspective on the value of land. At the same time, the close proximity of newly developed residential areas to farms is increasing the public demand for environmentally safe farming practices. By helping farmers to adopt practices that reduce chemical use and conserve limited resources, sustainable agriculture research and education can play a key role in building public support for agricultural land preservation. Educating land use planners and decisionmakers about sustainable agriculture is an important priority.

In Bangladesh, the condition of agricultural labour availability is getting more critical day by day due to increase disparity between urban and rural wages. Agricultural labour generally far below accepted social standards and legal protections in other forms of employment. Policies and programs are needed to address this problem, working toward socially just and safe employment that provides adequate wages, working conditions, health benefits, and chances for economic stability. To be more sustainable over the long-term, labour must be acknowledged and supported by government policies, recognized as important constituents of Land Grant Institute, and carefully considered when assessing the impacts of new technologies and practices.

Rural communities in Bangladesh are currently characterized by economic and environmental deterioration. Many are among the poorest locations in the nation. The reasons for the decline are complex, but changes in farm structure have played a significant role. Sustainable agriculture presents an opportunity to rethink the importance of family farms and rural communities. Economic development 
policies are needed that encourage more diversified agricultural production on family farms as a foundation for healthy economies in rural communities. In combination with other strategies, sustainable agriculture practices and policies can help foster community institutions that meet employment, educational, health, cultural and spiritual needs.

Consumers can play a critical role in creating a sustainable food system. For that case, the challenge now is to find strategies that broaden consumer perspectives, so that environmental quality, resource use, and social equity issues are also considered in shopping decisions. At the same time, new policies and institutions must be created to enable producers using sustainable practices to market their goods to a wider public. Coalitions organized around improving the food system are one specific method of creating a dialogue among consumers, retailers, producers and others. These coalitions or other public forums can be important vehicles for clarifying issues, suggesting new policies, increasing mutual trust, and encouraging a long-term view of food production, distribution and consumption.

\section{Issues / constrains}

- No single approach can be applied uniformly, heterogeneity in agro-climatic environment (agro-ecology, local and regional biophysical factors, and farmer characteristics), conditions need to adopt and the type of sustainable agriculture practice adopted,

- Amount and availability of biomass (e.g. crop residues, animal dung) is crucial element for the most Sustainable Agriculture practice for moisture conservation, soil fertility enhancement. Competing uses for biomass e.g. as cooking fuel or as fodder for cattle. Biomass constrained by limitedness of resource endowment,

- Economic incentives (e.g. prices) determine the profitable Sustainable Agriculture.

- Availability of information on net benefits of adoption, technical details on implementation of Sustainable Agriculture practices,

- There is no updating of extension workers skill to boost technical competence for sustainable agriculture, There is no updating of extension workers skill to boost technical competence for Sustainable Agriculture,

- Policy environment not conducive to widespread adoption of Sustainable Agriculture, both at the national and international level. There is lack of awareness by the policy maker on the benefit of Sustainable practices to possible resistance from agrochemical industries and other traditional actors in intensive agriculture supply,
- There is no policy exist that directly support sustainable agriculture. Even in Agriculture Policy (1999) have no specific clause or agenda on sustainable agriculture (NAP, 1999). Also National Seed Policy (1993) has no specific clause or agenda on sustainable agriculture (NSP, 1993).

\section{Role of Government on sustainable agriculture}

There is no structural support on sustainable agriculture in Bangladesh. Extension Education Department of Bangladesh Agricultural University has minor course on sustainable agriculture. This department is also available in the other Universities (Public/Science and Technology University). A little initiative has been taken by the NGOs like PROSHIKA, UNINIG, BARCIK, and Hunger Free World CARITAS in research and extension of sustainable agriculture (DFID, 2001). A number of NGOs (both local and international origin) implement (Farmers Field School) FFS and FFS type activities in Bangladesh. The Department of Agricultural Extension (DAE) of the Government also operates limited FFS. The FFS highlights the need for more location specific and broader extension approach with the farmers taking the lead role. This is a relatively new approach where farmers are protagonists and they have key role in technology development and testing. Integrated Pest Management (IPM), a new farm technology has a few methods under the technology being implemented by DAE and NGOs through FFS for sustainable agriculture. The government in its New Agricultural Extension Policy (NAEP) 1996 defined strategies to attain the prime objective of integrated environmental support defined that it would integrate environment into the overall agricultural policy to ensure a policy of sustainable agricultural development (NAEP, 1996).

\section{Conclusion}

Now incentives and policies for ensuring the sustainability of agriculture will be crucial if we are to meet the demands of improving yields without comprising environmental integrity or public health. Given emerging pressure and resource constraints, agricultural policies need to simultaneously help meet the triple objectives of socio-economy, agricultural production and environmental sustainability. A major challenge is to create policies, institutions, human resources and technologies that make the three goals more compatible. To maximize agriculture's efficiency and sustainability, public policy should seek to internalize all cost and benefits in the price of production inputs, such 
as improving pricing mechanisms for irrigation water, facilitating land market development, and eliminating distorting taxes and subsidies on agrochemical inputs, including fertilizers. Secure property rights and other policies offering farmers incentives for investing in resource management, as well as access to yield-increasing and resourceconserving technologies are critical.

\section{Recommendations}

1. To introduce sustainable agriculture practice for attaining household food security, livelihood, and finally alleviation of poverty,

2. Improve access to as well as the quality of information education and training program on sustainable agriculture for farmers and extension workers.

3. Policy advocacy and lobbying in favour of sustainable agriculture with GOs, NGOs, private and multilateral organizations.

4. More research and understanding needed on institutions links between applied research and farmer.

5. To raise awareness/social mobilization on sustainable agriculture.

6. Build up partnership with GO's, NGOs, networks, private sector, institutions, research organizations, other related organizations to promote sustainable agriculture.

7. To establish resource center on sustainable agriculture.

8. Ease biomass constraints e.g. provide modern cooking fuel to rural households; encourage incorporating forage legumes in the cropping systems.

\section{References}

ASR. 2006. Agriculture Sector Review (Crop sub sector). Actionable policy brief and resource Implications. Ministry of Agriculture, Govt. Republic of Bangladesh, Dhaka. pp. 14-51.

BRRI. 2010. Rice statistics in Bangladesh. Gazipur: Bangladesh Rice Knowledge Bank, Bangladesh Rice Research Institute. (http:// www.knowledgebank-brri.org/ riceinban.php).

BBS. 2008. Statistical Year Book of Bangladesh. Bangladesh Bureau of Statistics Division, Ministry of Planning, Govt. People's Republic of Bangladesh, Dhaka. pp. 121-134.

BER. 2009. Bangladesh Economic Review, Department of Finance, Ministry of Finance, Govt. People's Republic of Bangladesh. pp. 83-85.

Chowdhury, M.R. 2009. Population challenge facing Bangladesh. CW Post Campus, New York: Long Island University. (http:/ / www.fao.org/ fileadmin/ user_upload / fisheries/docs/Rice_Fish_Farming__Bangla desh.pdf).

DFID. 2001. Sustainable Agriculture Evaluation. Bangladesh Country Report. p-7, 85.
DFID. 2002. Sustainable Agriculture. Resource Management Key sheet 10. DFID: London UK

DoF. 2010. Fisheries statistical yearbook of Bangladesh 2008-2009. Dhaka: Fisheries Resources Survey System, Department of Fisheries, Ministry of Fisheries and Livestock. p. 1.

http:/ / www.attra.org

http:/ / www.sustainabletable.org

NAEP. 1996. New Agricultural Extension Policy, Ministry of Agriculture, Govt. People's Republic of Bangladesh. pp. 1-10.

NAP. 1999. National Agricultural Policy, Ministry of Agriculture, Govt. People's Republic of Bangladesh. pp. 1-23.

NSP. 1993. National Seed Policy, Ministry of Agriculture, Govt. People's Republic of Bangladesh. pp. 1-10.

Pretty. 1995. Regenerating Agriculture. Earthscan: London, UK.

Pretty. 2002. Agri-Culture: Reconnecting People, Land and Nature. Earthscan: London, UK.

USDA Farm Bill. 1990. United States Congress, 1990. Food, Agriculture, Conservation, and Trade Act of 1990, Public Law 101-624. Title XVI, Subtitle A, Section 1603. Washington, DC: US Government. 